\title{
Evaluation of Bidirectional Glenn Shunt
}

\author{
Dr. G. Praveen prabu ${ }^{1}$, Dr. G. K. Jaikaran ${ }^{2}$ \\ ${ }^{1}$ Resident Department Pediatric Cardiothoracic Surgery, Institute of Child Health and Hospital for children, \\ Egmore, Chennai, India ${ }^{2}$ Dr. G.K.Jaikaran, Professor, Department of Pediatric Cardiothoracic Surgery, \\ Institute of Child Health and Hospital for children, Egmore, Chennai, India
}

\begin{abstract}
A study was conducted to evaluate the outcomes of the bidirectional Glenn shunt technique performed between $2016 \mathrm{feb}$ and $2017 \mathrm{feb}, 14$ patients underwent bidirectional Glenn shunt. The patients consisted of 7 males and 7 females with age range of ( 2 to 10) years. In the 14 patients who underwent a bidirectional shunt operation, 7 patients were done without Cardio Pulmonary Bypass(off pump), 7 with Cardio Pulmonary Bypass. The results have been satisfactory in terms of lower Pulmonary Artery pressure, shorter duration of Ventilatory support, and less thoracic fluid drainage. Off-pump shunt offers more benefits than with Cardio Pulmonary Bypass. However, oxygen saturation had increased to the same degree in both groups at discharge. There was no operative mortality. All the patients were discharged without complications. This shunt technique is easy to perform and is helpful in the early management of patients with a functionally univentricular heart.
\end{abstract}

Keywords: Bidirectional Glenn shunt, Superior vena cava,Tetrology of fallot,Cardio pulmonary bypass, Pulmonary Artery Pressure.

\section{Introduction}

The bidirectional Glenn shunt (BDG) is an operation to divert systemic venous return from the superior vena cava (SVC) directly to both lungs through the right pulmonary artery (RPA), bypassing a hypoplastic or absent right ventricle. This cavopulmonary connection provides excellent palliation in complicated malformations associated with low pulmonary blood flow, low pulmonary arterial (PA) pressure, and low pulmonary vascular resistance. It raises systemic arterial oxygen saturation $\left(\mathrm{SaO}_{2}\right)$ by increasing the effective pulmonary blood flow. At the same time, it can relieve the volume load of the single functional ventricle and improve the geometric structure of the ventricle. ${ }^{1-2}$ If intracardiac repair is not necessary, the connection could be performed without cardiopulmonary bypass (CPB). ${ }^{3-4}$

Moreover, myocardial ischemia need not be applied during construction of the anastomosis outside the heart. Since CPB is known to activate inflammatory mediators, increase lung hydrostatic pressure, and decrease right ventricular compliance, off-pump surgery offers the advantage of reducing postoperative complications in these patients. In this study, we assessed the results of BDG performed between 1 year period.

\section{Patients And Methods}

A total of 14 patients, 7 male and 7 female, underwent BDG with or without CPB between 2016 feb and 2017 feb was evaluated. The procedure was the primary operation in all the cases. All the patients were examined preoperatively by electrocardiography, chest radiography, and echocardiography. Diagnosis in 14 of them was confirmed by echocardiogram and CT pulmonary angiogram for selected cases. Preoperative percutaneous oxygen saturation, $\mathrm{PA}$ pressure and $\mathrm{SaO}_{2}$ were monitored during and after the operation.

Table1. Patient Diagnosis

\begin{tabular}{|l|c|}
\hline \multicolumn{1}{|c|}{$\begin{array}{c}\text { Diagnosis } \\
\text { Dextrocardia+Singleventricle+situsinversus }\end{array}$} & $\begin{array}{c}\text { No. Of Cases } \\
(\mathbf{n = 1 4})\end{array}$ \\
\hline Ebstein anamoly & 1 \\
\hline $\begin{array}{l}\text { Double outlet right ventricle + } \\
\text { pulmonary stenosis }\end{array}$ & 3 \\
\hline $\begin{array}{l}\text { Transposition of the great arteries + } \\
\text { Pulmonary stenosis }\end{array}$ & 4 \\
\hline
\end{tabular}




\begin{tabular}{|l|l|}
\hline TOF+Pulmonary atresia & 4 \\
\hline Tetralogy of Fallot + endocardial cushion defect & 1 \\
\hline
\end{tabular}

The operation was performed at normal temperature with or without CPB through a median sternotomy. Pulsatile antegrade pulmonary blood flow through the pulmonary valve was maintained. At the beginning of the operation, Pulmonary Artery pressure as well as developments of the main, left, and right pulmonary arteries were examined, and systemic heparinization $(150 \mathrm{U} / \mathrm{kg})$ was administered.

In the 14 patients who underwent a bidirectional shunt operation, 7 patients with off pump, 7 patients on CPB. For those 7 patients who were done without CPB, a temporarily intra operative superior vena cava(SVC) - Right Atrial shunt was established. The SVC was cannulated near the innominate vein with a right-angled venous Cannula, which was connected through a short segment of pump tubing to another rightangled venous cannula placed in the right atrium. For the remaining 7 patients, AORTA, SVC, Inferior Vena Cava cannulated, CPB was established. Care was taken to avoid kinking. With this venous shunt opening, the SVC was occluded to check if blood pressure, SVC pressure, and oxygen saturation would change. Then the SVC was clamped and transected above the cavoatrial junction. The cardiac end of the SVC was closed with 6/0 polypropylene. Care must be taken not to damage the sino atrial node area. A large side-biting clamp was applied to the Right Pulmonary Artery, and a longitudinal incision of 1.5 to $2.0 \mathrm{~cm}$ was made on the superior aspect of the RPA. The distal end of the SVC was anastomosed end to side to the RPA with a running suture of 6/0 polypropylene. The clamp was then released, the temporary shunt removed, and heparin effect reversed.

\section{Results}

All patients had immediate improvement in $\mathrm{SaO}_{2}$ and showed an excellent postoperative response to the shunt. The mean duration of postoperative ventilatory support in off pump was $13 . \pm 7$. Hours, chest fluid drainage was $14 \pm 6 \mathrm{~mL} / \mathrm{kg}$. Mean PA pressure rise from $14 \pm 3 \mathrm{mmHg}$ at the beginning of the operation to $16.6 \pm 2.6 \mathrm{mmHg}$ in the early postoperative period. The mean duration of postoperative ventilatory support in on pump was $22 \pm 13$ hours, chest fluid drainage was $20 \pm 13 \mathrm{~mL} / \mathrm{kg}$. Mean PA pressure rise from $12 \pm$ $2 \mathrm{mmHg}$ at the beginning of the operation to $17 \pm 2 \mathrm{mmHg}$ in the early postoperative period. Cyanosis was clearly relieved at discharge from hospital, and $\mathrm{SaO}_{2}$ had increased to $92 \% \pm 4.0 \%$. There was no operative mortality. All the patients received antiplatelet treatment in the form of a small dose of aspirin (25 to $50 \mathrm{mg} /$ day) for 3 months or longer after the operation. There were no neurologic complications; no further arrhythmia occurred and so no antiarrhythmic medication was required.

For comparison, we analyzed the data of the 14 patients in the present study who underwent the shunt operation with and without CPB.

Table2. Comparison of Outcomes after Bidirectional Glenn Shunt With and Without Using Cardiopulmonary Bypass with mean values

\begin{tabular}{|l|c|c|}
\hline Variable & $\begin{array}{c}\text { Without CPB } \\
(\boldsymbol{n}=\mathbf{7})\end{array}$ & $\begin{array}{c}\text { With CPB } \\
(\boldsymbol{n}=\mathbf{7})\end{array}$ \\
\hline Age (years) & 5.7 & 4.8 \\
\hline Body surface area $\left(\mathrm{m}^{2}\right)$ & 0.72 & 0.65 \\
\hline Preoperative $\mathrm{SpO}_{2}(\%)$ & $76 \pm 7$ & $70 \pm 12$ \\
\hline Preoperative PA pressure $(\mathrm{mmHg})$ & $14 \pm 3$ & $12 \pm 2$ \\
\hline Postoperative PA pressure $(\mathrm{mmHg})$ & $16 \pm 2$ & $17 \pm 2$ \\
\hline Duration of ventilatory support $(\mathrm{h})$ & $13 \pm 7$ & $22 \pm 13$ \\
\hline Thoracic fluid drainage $(\mathrm{mL} / \mathrm{kg})$ & $14 \pm 6$ & $20 \pm 13$ \\
\hline Death & 0 & \\
\hline
\end{tabular}

$\mathrm{CPB}=$ Cardiopulmonary bypass; $\mathrm{PA}=$ Pulmonary artery; $\mathrm{SaO}_{2}=$ Arterial

oxygen saturation; $\mathrm{SpO}_{2}=$ Percutaneous oxygen saturation .

\section{Discussion}

After a series of experiments on the direct delivery of venous blood into the PA circulation, Glenn ${ }^{5}$ demonstrated the clinical use of an SVC-RPA shunt in 1958. Since then, a number of variations of the cavopulmonary shunt have been performed to provide palliation in cyanotic congenital heart disease. These included bidirectional cavopulmonary shunt between the SVC and the undivided $\mathrm{RPA}^{6}$ and total 
cavopulmonary connection (TCPC). ${ }^{7}$ All of these variations provided excellent palliation in patients with a single-ventricle heart, tricuspid atresia, or hypoplastic right ventricle syndrome. TCPC, whenever feasible, has been shown to be effective in treating these patients. However, in order to improve the outcome of TCPC, many centers advocate staging it with a bidirectional cavopulmonary shunt, a strategy that we have also adopted.

There is no consensus on the criteria for performing BDG. Most authors would suggest that the mean PA pressure should be less than $18 \mathrm{mmHg}$, or ideally below $15 \mathrm{mmHg}$. In contrast to a systemic pulmonary shunt, the cavopulmonary shunt does not increase ventricular work, thereby avoiding further ventricular hypertrophy and compliance reduction. In comparison with the classic Glenn shunt, BDG provides bilateral pulmonary blood flow, thereby avoiding the mismatch that may occur between the SVC flow volume and the cross-sectional area of the entire right lung.

The role of accessory pulmonary blood flow in the setting of a BDG remains contentious. An additional source of pulmonary blood flow may mitigate some of the benefits of a bidirectional cavopulmonary shunt physiology by offsetting the reduction in ventricular volume load and increasing the likelihood of pulmonary vascular complications. On the other hand, it may offer some advantages over a pure cavopulmonary shunt physiology: the increased $\mathrm{SaO}_{2}$ may be sufficient to reduce baseline cyanosis, and the additional source of pulmonary blood flow may allow for modestly improved exercise tolerance. In addition, by providing hepatic blood directly to the lungs, introducing an element of pulsatility to the pulmonary flow and increasing flow rates, an additional source of pulmonary flow may in fact reduce the likelihood of pulmonary vascular complications (such as arteriovenous fistulas and aortopulmonary collaterals) and improve pulmonary artery growth. ${ }^{2}$

CPB plays a vital role in cardiac surgery. However, it may activate inflammatory mediators as well as lead to lung injury and blood cell destruction. These adverse effects can increase pulmonary vascular resistance and decrease pulmonary blood flow after cavopulmonary connection. For this reason, we try, whenever possible, to create the shunt off-pump at normal temperature. The results have so far been satisfactory. Comparing the results BDG with or without CPB, the off-pump group showed better postoperative results in terms of lower PA pressure, shorter duration of ventilatory support, and less thoracic fluid drainage. However, oxygen saturation had increased to the same degree in both groups at discharge. Off-pump offers more benefits than with CPB.

There is certainly no unanimity on the criteria for performing a bidirectional cavopulmonary connection. ${ }^{10,11,12}$ Most authors would suggest that mean PA pressure should be less than $18 \mathrm{~mm} \mathrm{Hg}$, ideally less than $15 \mathrm{~mm} \mathrm{Hg}$, with a calculated pulmonary vascular resistance of less than $2.0 \mathrm{u} / \mathrm{m}^{2}$. Although there are some general guidelines as to the caliber of PA acceptable for cavopulmonary anastomosis, it is acknowledged that these measurements do not take into consideration the compliance of the vascular bed, the so-called maturity of the pulmonary bed, or the most peripheral and intra parenchymal pulmonary arteries. PA distortion defined as peripheral PA Stenosis, hypoplasia, or discontinuity, remains a risk factor for suboptimal operative outcome. The timing of cavopulmonary anastomosis is poorly defined. We believe it can be performed at approximately 6 months of age; others have indicated that it can be carried out at any age after the pulmonary vascular resistance has reached its nadir. ${ }^{13}$ Some have applied the technique in very young patients. ${ }^{14}$ It was found to facilitate ventricular volume unloading and regression of ventricular mass in younger children ( $<1$ year old), and the beneficial effect on ventricular end-diastolic volume and mass is clearly age-dependent, with older patients benefiting less in terms of enhanced systemic oxygen saturation. ${ }^{15}$ Older age might be a risk factor for postoperative cyanosis because of the lower proportion of caval return from the SVC relative to the inferior vena cava in the older child. ${ }^{16}$.However, the risk of these late complications are thought by most authors to be lower in BDG, especially when Pulsatile antegrade pulmonary blood flow is maintained. ${ }^{2,9}$

\section{Conclusion}

In conclusion, Bidirectional glenn shunt provides excellent palliation for selected patients with cyanotic congenital heart disease. The results have been satisfactory, off-pump shunt offers more benefits than with CPB interms of lower PA pressure, shorter duration of ventilatory support, and less thoracic fluid drainage. However, oxygen saturation had increased to the same degree in both groups at discharge . Long term follow-up is needed for these patients.

\section{References}

[1]. Freedom RM, Nykanen D, Benson LN. The physiology of the bidirectional cavopulmonary connection, Ann Thorac Surg1998; 66: 664-7. 
[2]. McElhinney DB, Marianeschi SM, Reddy VM. Additional pulmonary blood flow with the bidirectional Glenn anastomosis: does it make a difference? Ann Thorac Surg 1998;66: 668-72.

[3]. Okabe H, Nagata N, Kaneko Y, Kobayashi J, Kanemoto S, Takaoka T. Extracardiac cavopulmonary connection of Fontan procedure with autologous pedicled pericardium without cardiopulmonary bypass, J Thorac Cardiovasc Surg 1998;116:1073-5.

[4]. Burke RP, Jacobs JP, Ashraf MH, Aldousany A, Chang AC.Extracardiac Fontan operation without cardiopulmonary bypass,

[5]. Ann Thorac Surg 1997;63:1175-7.

[6]. Glenn WW. Circulatory bypass of the right side of the heart. IV.Shunt between superior vena cava and distal right pulmonary artery; report of clinical application,

[7]. N Engl J Med 1958;259: 117-20.

[8]. Abrams LD. Side to side cavopulmonary anastomosis for the palliation of "primitive ventricle" [abstract],Br Heart $\mathbf{J}$ 1977;39:926.

[9]. Kawashima Y, Kitamura S, Matsuda H, Shimazaki Y, Nakano S, Hirose H. Total cavopulmonary shunt operation in complex cardiac anomalies, A new operation, J Thorac Cardiovasc Surg 1984;87: 74-81.

[10]. Lamberti JJ, Spicer RL, Waldman JD, Grehl TM, Thomson D, George L, et al. The bidirectional cavopulmonary shunt, J Thorac Cardiovasc Surg 1990;100: 22-9.

[11]. Muster AJ, Zales VR, Ilbawi MN, Backer CL, Duffy CE, Mavroudis C. Biventricular repair of hypoplastic right ventricle assisted by pulsatile bidirectional cavopulmonary anastomosis, J Thorac Cardiovasc Surg 1993;105:112-9.

[12]. Hopkins RA, Armstrong BE, Serwer GA, Peterson RJ, Oldham HN Jr. Physiological rationale for a bidirectional cavopulmonary shunt.

[13]. A versatile complement to the Fontan principle, J Thorac Cardiovasc Surg 1985;90:391-8.

[14]. Van Arsdell GS, Williams WG, Maser CM, Streitenberger KS, Rebeyka IM, Coles JG, et al. Superior vena cava to pulmonary artery anastomosis: an adjunct to biventricular repair, J Thorac Cardiovasc Surg 1996;112:1143-9.

[15]. Jonas RA. Indications and timing for the bidirectional Glenn shunt versus the fenestrated Fontan circulation, J Thorac Cardiovasc Surg 1994;108:522-4.

[16]. Lamberti JJ, Spicer RL, Waldman JD, Grehl TM, Thomson D, George L, et al. The bidirectional cavopulmonary shunt ,.J Thorac Cardiovasc Surg 1990;100:22-30.

[17]. Reddy VM, Liddicoat JR, Hanley FL. Primary bidirectional superior cavopulmonary shunt in infants between 1 and 4 months of age, Ann Thorac Surg 1995,59:1120-5.

[18]. Forbes TJ, Gajarski R, Johnson GL, Reul GJ, Ott DA, Drescher K, et al. Influence of age on the effect of bidirectional cavopulmonary anastomosis on left ventricular volume, mass and ejection fraction, J Am Coll Cardiol 1996;28:1301-7.

[19]. Gross GJ, Jonas RA, Castaneda AR, Hanley FL, Mayer JE Jr, Bridges ND. Maturational and hemodynamic factors predictive of increased cyanosis after bidirectional cavopulmonary anastomosis, Am J Cardiol 1994;74:705-9. 